\title{
Early Cretaceous multituberculate mammals from the Kuwajima Formation (Tetori Group), central Japan
}

\author{
Nao Kusuhashi \\ Acta Palaeontologica Polonica 53 (3), 2008: 379-390 doi:http://dx.doi.org/10.4202/app.2008.0302
}

Hakusanobaatar matsuoi gen. et sp. nov. and Tedoribaatar reini gen. et sp. nov. are multituberculate mammals recovered from the Lower Cretaceous (Barremian to lower Aptian) Kuwajima Formation of the Tetori Group in the Shiramine district, Hakusan City, Ishikawa Prefecture, central Japan. Hakusanobaatar matsuoi is an eobaatarid multituberculate characterized by a P4with cusp formula 3:5, and a P5 with cusp formula 2:6:?2. One of the specimens of $H$. matsuo $i$ has the best preserved upper premolar series among known eobaatarid specimens. Based on the dentition of $H$. matsuoi, it is highly probable that the cimolodontan P4 is homologous with the "plagiaulacidan" P5. Tedoribaatar reini is also tentatively attributed to Eobaataridae, and shows a single-rooted p3 and loss of at least the permanent p2. On the basis of these apomorphic features, T. reini is considered to be the "plagiaulacidan" multituberculate that is most closely related to cimolodontans.

Key words: Mammalia, Multituberculata, Eobaataridae, Hakusanobaatar, Tedoribaatar, Early Cretaceous, Kuwajima Formation, Tetori Group, Japan

Nao Kusuhashi [nao kusuhashi@ivpp.ac.cn], Institute of Vertebrate Paleontology and Paleoanthropology, Chinese Academy of Sciences, Beijing 100044, People's Republic of China, and Department of Geology and Mineralogy, Graduate School of Science, Kyoto University, Kyoto 606-8502, Japan.

This is an open-access article distributed under the terms of the Creative Commons Attribution License (for details please see creativecommons.org), which permits unrestricted use, distribution, and reproduction in any medium, provided the original author and source are credited. 
